\title{
A retrospective case series of ultrasound-guided suprascapular nerve pulsed radiofrequency treatment for hemiplegic shoulder pain in patients with chronic stroke
}

This article was published in the following Dove Press journal:

Journal of Pain Research

\begin{abstract}
Alessandro Picelli, ${ }^{1,2}$ Davide Lobba,' Patrizia Vendramin, ${ }^{3}$ Giuseppe Castellano, ${ }^{3}$ Elena Chemello,' Vittorio Schweiger, ${ }^{4,5}$ Alvise Martini, ${ }^{4,5}$ Massimo Parolini, ${ }^{4,5}$ Marialuisa Gandolfi, ${ }^{1,2}$ Enrico Polati, ${ }^{4,5}$ Nicola Smania ${ }^{1,2}$

'Neuromotor and Cognitive Rehabilitation Research Center, Department of Neurosciences, Biomedicine and Movement Sciences, University of Verona, Verona, Italy; ${ }^{2}$ Neurorehabilitation Unit, Department of Neurosciences, Hospital Trust of Verona, Verona, Italy; ${ }^{3}$ Anesthesia, Intensive Care and Pain Therapy Unit, "Girolamo Fracastoro" Hospital, San Bonifacio, Italy; ${ }^{4}$ Anesthesia and Intensive Care Section, Department of Surgery, Dentistry, Pediatrics and Gynecology, University of Verona, Verona, Italy; ${ }^{5}$ Pain Therapy Center, Department of Emergency and Intensive Care, Hospital Trust of Verona, Verona, Italy
\end{abstract}

Correspondence: Alessandro Picelli Neuromotor and Cognitive Rehabilitation Research Center, Department of Neurosciences, Biomedicine and Movement Sciences, University of Verona, Piazzale LA Scuro, 10, 37।34

Verona, Italy

Tel +390458124573

Fax +39045812 4495

Email alessandro.picelli@univr.it
Purpose: Hemiplegic shoulder pain (HSP) is the most common pain condition after stroke. Pulsed radiofrequency (PRF) treatment of the suprascapular nerve (SSN) effectively relieves shoulder pain conditions. To date, there is no study about the effects of PRF treatment for HSP. Thus, our aim was to report on a case series about its use in chronic stroke.

Patients and methods: Six chronic stroke patients with HSP (visual analog scale [VAS] score for pain $\geq 30 \mathrm{~mm}$ ) underwent ultrasound-guided SSN PRF treatment. All were evaluated before treatment and at 4 and 16 weeks of follow-up. The main outcome was VAS score. Secondary outcomes were Modified Ashworth Scale, shoulder passive range of motion (PROM), Disability Assessment Scale (DAS), Fugl-Meyer Assessment, and EuroQol-5 dimension questionnaire (EuroQol-5D) scores.

Results: As compared with baseline, improvement was observed in the following parameters: VAS for pain (at 4 weeks, $P=0.023$; at 16 weeks, $P=0.023$ ); shoulder PROM for abduction (at 4 weeks, $P=0.023$; at 16 weeks, $P=0.024$ ), flexion (at 4 and 16 weeks, $P=0.024$ ), extension (at 4 and 16 weeks, $P=0.02$ ), and external rotation ( 4 and 16 weeks, $P=0.02$ ); DAS for hygiene (at 4 and 16 weeks, $P=0.024$ ), dressing (at 4 weeks, $P=0.02$; at 16 weeks, $P=0.024$ ), and pain (at 4 weeks, $P=0.024$; at 16 weeks, $P=0.023$ ); and EuroQol-5D (at 4 and 16 weeks, $P=0.024$ ). Conclusion: Our observations support the use of ultrasound-guided SSN PRF treatment for HSP in chronic stroke patients.

Keywords: chronic pain, pain management, rehabilitation

\section{Introduction}

Hemiplegic shoulder pain (HSP) is the most common pain condition in stroke patients and a major contributor to poststroke disability. ${ }^{1,2}$ Its multifactorial etiology includes impaired motor function (muscle tone changes), soft tissue lesions (rotator cuff and biceps tendon disorders, adhesive capsulitis), and altered peripheral or central nervous system (CNS) activity (complex regional pain syndrome type 1 , peripheral nerve entrapment, neglect, sensory impairment, central pain, central sensitization)..$^{3,4}$

Radiofrequency treatments are offered for various pain syndromes according to the assumption that selectively heating nervous structures can impede nociceptive input. ${ }^{5}$ From a technical point of view, they can be delivered using a continuous modality or a pulsed one. ${ }^{5,6}$ Continuous radiofrequency $(\mathrm{CRF})$ is a neurolytic technique that applies heat for selective destruction of pain-carrying nerve fibers (A- $\delta$ and $C$ fibers $).{ }^{5}$ It uses a 
constant high-frequency alternating current to induce coagulative necrosis at the target tissue by producing temperatures $\geq 45^{\circ} \mathrm{C}$. ${ }^{6}$ Considering the possible adverse events of CRF neuroablation (eg, lasting motor deficits, neuritis and deafferentation pain), pulsed radiofrequency (PRF) was developed as an alternative modality that uses short, high-voltage current bursts to obtain more reversible and less destructive effects than $\mathrm{CRF}^{5-7}$ As to the mechanism of action of PRF, to date, most studies point toward a neuromodulatory-type effect based on an alteration in synaptic transmission. ${ }^{8,9}$ However, there is an ongoing discussion about the lesioning effect of PRF. In particular, Cosman and Cosman ${ }^{10}$ and Cosman et $\mathrm{al}^{11}$ reported that PRF produces heat bursts (with temperatures in the range) associated with destructive heat lesions (whose size is affected also by the tip gage, tip length, and time). Nevertheless, PRF has demonstrated a remarkable margin of safety. ${ }^{9}$

To provide pain relief and facilitate rehabilitation of patients with shoulder pain, physicians often perform suprascapular nerve (SSN) block as a useful management in various conditions. ${ }^{12-16}$ This can be done by means of analgesics, corticosteroid, and electrical stimulation techniques. ${ }^{14,15}$ As to the use of SSN PRF treatment for shoulder pain, a good clinical efficacy lasting for 6 months with scant complications has been reported in the literature. ${ }^{17,18}$

With regard to patients with stroke, the SSN block injection with corticosteroid and anesthetic was found to be effective and safe for the treatment of HSP. ${ }^{19}$ Even if this is in line also with our daily practice, we have a growing clinical experience concerning the use of SSN PRF treatment for HSP in order to obtain more stable and long-lasting effects. Unfortunately, to date, there is no study on it. Thus, our aim was to report on a case series about the effects of ultrasound-guided SSN PRF treatment in chronic stroke patients with HSP.

\section{Patients and methods}

This single-center, retrospective, chart review case series analyzed data from six chronic stroke patients with HSP who had undergone ultrasound-guided SSN PRF treatment at our Clinical Unit from February 2017 to June 2017.

The inclusion criteria were age $\geq 18$ years, first-ever unilateral stroke, Mini Mental State Examination $\geq 24,{ }^{20}$ HSP $\geq 30 \mathrm{~mm}$ on the visual analog scale (VAS), ${ }^{21}$ time since stroke $>6$ months, and time since last botulinum toxin treatment $>6$ months. The exclusion criteria were participation in other trials, change in pain medication during the follow-up period, aphasia, neurolytic or surgical procedures for upper limb spasticity, and other conditions at the affected shoulder (rotator cuff disorders, frozen shoulder, thoracic outlet syndrome, osteoarthritis, bursitis, recent trauma, bone fracture, joint replacement).

All participants were outpatients. All patients provided written informed consent, which included consent for data extraction from chart review as needed. The study was carried out according to the Declaration of Helsinki and approved by the local ethics committee (Comitato Etico per la Sperimentazione Clinica delle Province di Verona e Rovigo). Patients did not participate in any rehabilitation program during the follow-up period.

\section{Treatment procedures}

All patients were treated by the same physician. PRF was performed with the patient in the sitting position during the whole procedure. Before treatment, local anesthesia to the cutaneous and subcutaneous tissues was administered with $2 \mathrm{~mL}$ of lidocaine $2 \%$. A 22-gage, $100 \mathrm{~mm}, 5 \mathrm{~mm}$ active-tip radiofrequency needle was guided to the suprascapular notch under ultrasonography (linear transducer with a scanning frequency of $12 \mathrm{MHz}$ ). ${ }^{22}$ Anatomic landmarks were used for transducer position (the spine of the scapula, the acromion and the acromial end of the clavicle, and the coracoid process) and SSN localization (the trapezius muscle, the supraspinatus muscle, the supraspinous fossa, and the suprascapular and the spinoglenoid notch). The SSN was identified as a hyperechoic structure 3-4 cm deep and below the transverse scapular ligament in the scapular notch. ${ }^{23}$ Following elicitation of paresthesia response in the shoulder region to a $50 \mathrm{~Hz}, 1 \mathrm{~ms}$, $0.5 \mathrm{~V}$ sensorial stimulus and appropriate muscular response to a $2 \mathrm{~Hz}, 1 \mathrm{~ms}, 0.4 \mathrm{~V}$ motor stimulus, PRF treatment was applied at $485 \mathrm{kHz}, 42 \mathrm{~V}, 20 \mathrm{~ms}, 42^{\circ} \mathrm{C}$ for $300 \mathrm{~s}$ ( $5 \mathrm{~min}$; TherMedico NK1; schwa-medico GmbH, Ehringshausen, Germany). ${ }^{22,23}$ Patients were discharged if no significant complications occurred (eg, pain, bleeding, or pneumothorax).

\section{Evaluation procedure}

All patients were evaluated before treatment (T0), at 4 weeks (T1), and at 16 weeks (T2) of follow-up. Patients remained seated during the evaluation procedure.

\section{Primary outcome}

The primary outcome was the VAS for pain, which consists of a $100 \mathrm{~mm}$ vertical line anchored with extremes of subjective pain. ${ }^{21}$ 


\section{Secondary outcomes}

Secondary outcomes were the Modified Ashworth Scale (MAS), the shoulder passive range of motion (PROM), the Disability Assessment Scale (DAS), the Fugl-Meyer Assessment (FM), and the EuroQol-5 dimension questionnaire (EQ-5D).

The MAS was used to measure shoulder adductor muscles tone. This 6-point scale grades resistance to rapid passive stretch from 0 (no increase in muscle tone) to 5 (joint is rigid). ${ }^{24,25}$ Shoulder flexion, extension, abduction, and external rotation PROM was measured using a handheld goniometer. Measurement sensitivity was arbitrarily set at $5^{\circ}{ }^{26}$ The DAS was used to evaluate the extent of functional impairment in the domains of patient hygiene, dressing, limb position, and pain as follows: 0 , no disability; 1 , mild disability; 2 , moderate disability; and 3 , severe disability. ${ }^{27,28}$ The FM was used to evaluate the ability of the affected upper limb to perform selective movements. The maximum score on the FM upper limb section was 66, with subscores of 36 for the upper arm, 10 for the wrist, 14 for the hand, and 6 for coordination and speed of movement. ${ }^{29}$ Quality of life was assessed by the EQ-5D score on a visual scale from 0 (worst imaginable health state) to 100 (best imaginable health state). ${ }^{30}$

\section{Statistical analysis}

Statistical analysis was carried out using the Statistical Package for Social Sciences for Macintosh, version 20.0 (IBM Corporation, Armonk, NY, USA). The Wilcoxon signed-rank test was applied to compare differences in $\mathrm{T} 1$ vs $\mathrm{T} 0$ and $\mathrm{T} 2$ vs $\mathrm{T} 0$. The alpha level for significance was set at $P<0.05$. The Bonferroni correction was used for multiple comparisons, resulting in $P<0.025$ as the significance threshold.

\section{Results}

No adverse events occurred during the follow-up period. Table 1 presents the demographic and clinical characteristics of each patient.

\section{Primary outcome}

Significant improvements on the VAS after PRF treatment of the SSN were observed at T1 $(P=0.023 ; Z=-2.27)$ and T2 ( $P=0.023 ; Z=-2.27$; Table 2).

\section{Secondary outcomes}

No significant improvement in the MAS score was found at $\mathrm{T} 1$ and T2. Significant improvements in the PROM of shoulder abduction were found at $\mathrm{T} 1(P=0.023 ; Z=-2.271)$ and T2 $(P=0.024 ; Z=-2.264)$, shoulder flexion at T1 $(P=0.024$; $Z=-2.25)$ and $\mathrm{T} 2(P=0.024 ; Z=-2.25)$, shoulder extension at T1 $(P=0.02 ; Z=-2.33)$ and $\mathrm{T} 2(P=0.02 ; Z=-2.33)$, and external rotation at $\mathrm{T} 1(P=0.02 ; Z=-2.33)$ and $\mathrm{T} 2(P=0.02$; $Z=-2.33)$. Significant improvements in the DAS score for hygiene were found at $\mathrm{T} 1(P=0.024 ; Z=-2.25)$ and $\mathrm{T} 2$ $(P=0.024 ; Z=-2.25)$, dressing at $\mathrm{T} 1(P=0.02 ; Z=-2.33)$ and T2 $(P=0.024 ; Z=-2.264)$, and pain at T1 $(P=0.024$; $Z=-2.264)$ and $\mathrm{T} 2(P=0.023 ; Z=-2.271)$ but for limb position. No significant improvement in FM was found at T1 and T2. Significant improvements in the EQ-5D were found at T1 $(P=0.024 ; Z=-2.264)$ and T2 $(P=0.024 ; Z=-2.264$; Table 2$)$.

\section{Discussion}

The SSN provides $70 \%$ of sensory innervation to the shoulder joint. ${ }^{31}$ In chronic shoulder pain conditions, the afferent fibers of SSN may become entrapped by injured tissues or sensitized due to chronic pain. ${ }^{13,32}$ The SSN block provides temporary cessation of nociceptive information from the affected shoulder to CNS. ${ }^{12-16}$ Previous studies involving patients with HSP mainly focused on SSN block by combining local anesthetics with cortisone. ${ }^{19,26,33-36}$ Early studies on this issue were contradictory. Lee and Khunadorn ${ }^{37}$ reported poor efficacy of SSN block on HSP relief, whereas Boonsong et al ${ }^{33}$ claimed that blocking the SSN was safe and effective for HSP. A later, properly sized, randomized controlled trial by Adey-Wakeling et al ${ }^{19}$ supported Boonsong et al's findings about the superiority of SSN block ( $1 \mathrm{~mL}$ of $40 \mathrm{mg} / \mathrm{mL}$ methylprednisolone + $10 \mathrm{~mL}$ of $0.5 \%$ bupivacaine hydrochloride) on placebo for

Table I Demographic and clinical characteristics of patients

\begin{tabular}{lllllll}
\hline Characteristics & Patient I & Patient 2 & Patient 3 & Patient 4 & Patient 5 & Patient 6 \\
\hline Age (years) & 61 & 70 & 65 & 55 & 76 & 65 \\
Sex & Male & Female & Female & Female & Male & Male \\
Time since stroke onset (years) & 2 & 5 & 9 & 2 & 4 & 7 \\
DN4 (score) & 4 & 1 & 0 & 1 & 0 & 7 \\
Pain medication & Opioids & NSAIDs & NSAIDs & Opioids & Opioids & Opioids \\
\hline
\end{tabular}

Abbreviations: DN4, Douleur Neuropathique in 4 Questions; NSAIDs, non-steroidal anti-inflammatory drugs. 
Table 2 Data at all time points and comparisons of treatment effects on all outcome measures

\begin{tabular}{|c|c|c|c|c|c|}
\hline \multirow[t]{2}{*}{ Outcomes } & \multirow{2}{*}{$\begin{array}{l}\text { Before } \\
\text { treatment (T0) }\end{array}$} & \multirow{2}{*}{$\begin{array}{l}\text { 4-week follow-up } \\
\text { (TI) }\end{array}$} & \multirow{2}{*}{$\begin{array}{l}\text { I6-week follow- } \\
\text { up (T2) }\end{array}$} & \multicolumn{2}{|c|}{ Wilcoxon signed-rank test } \\
\hline & & & & $\begin{array}{l}\text { TI vs T0, } \\
P \text { value }(Z)\end{array}$ & $\begin{array}{l}\text { T2 vs T0, } \\
P \text { value (Z) }\end{array}$ \\
\hline VAS $(0-100 \mathrm{~mm})$, mean (SD) & $88.3(7.5)$ & $15.0(12.2)$ & II.7 (9.8) & $0.023(-2.27 I)^{*}$ & $0.023(-2.27 \mathrm{I})^{*}$ \\
\hline $\begin{array}{l}\text { MAS shoulder adductors }(0-5) \text {, } \\
\text { median (IQR) }\end{array}$ & $1.50(1.00 ; 3.00)$ & $1.00(1.00 ; 2.00)$ & $1.00(1.00 ; 2.00)$ & $0.083(-1.732)$ & $0.083(-1.732)$ \\
\hline $\begin{array}{l}\text { Shoulder flexion PROM (degrees), } \\
\text { mean (SD) }\end{array}$ & $73.3(28.8)$ & $98.3(28.6)$ & $98.3(28.6)$ & $0.024(-2.25 \mathrm{I})^{*}$ & $0.024(-2.25 \mathrm{I})^{*}$ \\
\hline $\begin{array}{l}\text { Shoulder extension PROM (degrees), } \\
\text { mean (SD) }\end{array}$ & $38.3(4.1)$ & $50.0(1.5)$ & $50.0(2.7)$ & $0.020(-2.333)^{*}$ & $0.20(-2.333)^{*}$ \\
\hline $\begin{array}{l}\text { Shoulder abduction PROM (degrees), } \\
\text { mean (SD) }\end{array}$ & $71.7(19.4)$ & $105.0(16.4)$ & $106.7(16.3)$ & $0.023(-2.27 I)^{*}$ & $0.024(-2.264)^{*}$ \\
\hline $\begin{array}{l}\text { Shoulder external rotation PROM (degrees), } \\
\text { mean (SD) }\end{array}$ & $34.2($ (II.I) & $45.8(9.2)$ & $45.8(9.1)$ & $0.020(-2.333)^{*}$ & $0.20(-2.333)^{*}$ \\
\hline DAS hygiene (0-3), median (IQR) & $3.00(2.75 ; 3.00)$ & $1.00(1.00 ; 2.00)$ & $0.00(0.00 ; 1.00)$ & $0.024(-2.25 \mathrm{I})^{*}$ & $0.024(-2.251)^{*}$ \\
\hline DAS dressing (0-3), median (IQR) & $2.50(1.75 ; 3.00)$ & $1.00(0.75 ; 2.00)$ & $0.00(0.00 ; 1.00)$ & $0.020(-2.333)^{*}$ & $0.024(-2.264)^{*}$ \\
\hline DAS limb position (0-3), median (IQR) & $2.50(0.75 ; 3.00)$ & $0.50(0.00 ; 1.00)$ & $0.25(0.00 ; 1.00)$ & $0.04 I(-2.04 I)$ & $0.039(-2,060)$ \\
\hline DAS pain (0-3), median (IQR) & $2.50(2.00 ; 3.00)$ & $0.00(0.00 ; 1.25)$ & $0.00(0.00 ; 0.25)$ & $0.024(-2.264)^{*}$ & $0.023(-2.271)^{*}$ \\
\hline FM upper limb, median (IQR) & $8.50(4.75 ; 21.00)$ & $9.00(4.75 ; 27.25)$ & $9.00(4.75 ; 27.25)$ & $0.102(-1.633)$ & $0.102(-1.633)$ \\
\hline EQ-5D, median (IQR) & $50.00(37.50 ; 52.50)$ & $70.00(60.00 ; 80.00)$ & $75.00(67.50 ; 80.00)$ & $0.024(-2.264)^{*}$ & $0.024(-2.264)^{*}$ \\
\hline
\end{tabular}

Note: *Statistically significant after the Bonferroni correction $(P<0.025)$.

Abbreviations: VAS, visual analog scale; SD, standard deviation; MAS, Modified Ashworth Scale; IQR, interquartile range; PROM, passive range of motion; DAS, Disability Assessment Scale; FM, Fugl-Meyer Assessment; EQ-5D, EuroQol-5 dimension questionnaire.

reducing HSP intensity. The effectiveness of SSN block by combining local anesthetics with cortisone has been further confirmed in long-term chronic stroke patients with HSP. ${ }^{26}$ With regard to our clinical practice, we usually treat (subacute or chronic) stroke patients with HSP by means of pain (oral) medication (mainly using non-steroidal anti-inflammatory drugs or opioids; Table 1). In the case of scant pain reduction, we then perform SSN block by combining local anesthetics with cortisone in order to obtain a relief of pain and consequently facilitate neurorehabilitation. In the case of patients with short-lasting benefits after pharmacological SSN block, we provide ultrasound-guided SSN PRF treatment with a growing positive experience. Thus, from this point of view, the anesthetic SSN block might be considered also as a test for the effectiveness of treating SSN in patients with HSP. To the best of our knowledge, this is the first report about the effects of ultrasound-guided SSN PRF treatment in chronic stroke patients with HSP. As to the primary outcome, we observed a significant reduction in pain intensity up to 16 weeks after PRF treatment. This is in keeping with previous findings about the long-term (up to 6 months) effects of PRF SSN treatment. ${ }^{17}$ As to secondary outcomes, we observed that PRF treatment of the SSN might effectively lead to increased shoulder PROM, reduced joint disability, and improved quality of life up to 16 weeks after treatment. This is very relevant for rehabilitation. Indeed, while pain relief accompanied improvement in PROM and quality of life, also reducing self-rated disability of the affected upper limb, our findings indicate the need for combining physical rehabilitation and antispastic drugs with analgesic strategies to reduce muscle tone and obtain functional improvements. ${ }^{38,39}$ Thus, PRF treatment of the SSN might be proposed as a treatment option in stroke rehabilitation to facilitate shoulder mobilization and neuromotor techniques in patients with HSP.

To date, the mechanism of action of PRF treatment for pain relief is still an object of debate. From a physical point of view, the leading explanation for PRF effects is low electric field phenomenon that may induce a long-term depression of synaptic transmission..$^{9}$ On the other hand, from a biological point of view, PRF seems to have effects also on cell morphology and pain signaling. ${ }^{9}$ In particular, PRF may enhance the descending noradrenergic and serotonergic inhibitory pathways, which are involved in pain modulation mechanisms. ${ }^{40}$ Furthermore, a neuromodulatory effect has been suggested via alternating gene expression (eg, c-Fos, ATF-3) in pain processing neurons by which PRF treatment may provide long-lasting pain relief., ${ }^{9,41}$ On these bases, in order to interpret our observations, we might suggest 
a potential reduction in central sensitization secondary to a decrease in nociceptive stimuli, which would be in line with the hypothesized nociceptive and neuropathic nature of HSP. ${ }^{3}$ Moreover, we cannot exclude some kinds of neural tissue modification due to the PRF transient "heat spikes" $\left(\sim 45^{\circ} \mathrm{C}\right.$ to $50^{\circ} \mathrm{C}$ around the needle tip, depending on the tissue impedance as reported in the literature), whose ablative effect is unknown. ${ }^{10}$

This study has several limitations. First, it did not have a prospective design and the sample size was small. We estimated that a total of 27 patients would provide $90 \%$ power to detect a difference of $13 \mathrm{~mm}$ on the VAS (minimal clinically important difference) at the primary end point. ${ }^{42}$ Second, there was no control group treated with placebo or other treatments (eg, intra-articular injection, local anesthesia, botulinum toxin, physical therapy) for shoulder pain. Third, no further ultrasound evaluation of the SSN was done after PRF. Thus, we have no information about any SSN structural change or nerve echo signal modification after treatment.

\section{Conclusion}

Our observations support the use of ultrasound-guided SSN PRF treatment for HSP in chronic stroke patients. Future larger randomized controlled trials are desirable to produce new findings and possibly confirm ours about this issue.

\section{Author contributions}

All authors contributed toward data analysis, drafting and critically revising the paper, gave final approval of the version to be published, and agree to be accountable for all aspects of the work.

\section{Disclosure}

The authors report no conflicts of interest in this work.

\section{References}

1. Adey-Wakeling Z, Arima H, Crotty M, et al; SEARCH Study Collaborative. Incidence and associations of hemiplegic shoulder pain poststroke: prospective population-based study. Arch Phys Med Rehabil. 2015;96(2):241-247.e1.

2. Wang L, Tao Y, Chen Y, Wang H, Zhou H, Fu X. Association of post stroke depression with social factors, insomnia, and neurological status in Chinese elderly population. Neurol Sci. 2016;37(8):1305-1310.

3. Jones AK, Brown CA. Post-stroke shoulder pain: nociceptive or neuropathic? Pain. 2013;154(2):189.

4. Coskun Benlidayi I, Basaran S. Hemiplegic shoulder pain: a common clinical consequence of stroke. Pract Neurol. 2014;14(2):88-91.

5. Cahana A, Vutskits L, Muller D. Acute differential modulation of synaptic transmission and cell survival during exposure to pulsed and continuous radiofrequency energy. J Pain. 2003;4(4):197-202.
6. Uchida K. Radiofrequency treatments for neuropathic pain: review and new approaches. In: Udeagha C, editor. Neuropathic Pain. Rijeka, HR: InTech; 2012:123-140.

7. Rohof OJ. Radiofrequency treatment of peripheral nerves. Pain Pract. 2002;2:257-260.

8. Cahana A, Van Zundert J, Macrea L, van Kleef M, Sluijter M. Pulsed radiofrequency: current clinical and biological literature available. Pain Med. 2006;7(5):411-423.

9. Chua NH, Vissers KC, Sluijter ME. Pulsed radiofrequency treatment in interventional pain management: mechanisms and potential indicationsa review. Acta Neurochir (Wien). 2011;153(4):763-771.

10. Cosman ER Jr, Cosman ER Sr. Electric and thermal field effects in tissue around radiofrequency electrodes. Pain Med. 2005;6(6):405-424.

11. Cosman ER Jr, Dolensky JR, Hoffman RA. Factors that affect radiofrequency heat lesion size. Pain Med. 2014;15(12):2020-2036.

12. Chang KV, Wu WT, Hung CY, et al. Comparative effectiveness of suprascapular nerve block in the relief of acute post-operative shoulder pain: a systematic review and meta-analysis. Pain Physician. 2016;19(7):445-456.

13. Chang KV, Hung CY, Wu WT, Han DS, Yang RS, Lin CP. Comparison of the effectiveness of suprascapular nerve block with physical therapy, placebo, and intra-articular injection in management of chronic shoulder pain: a meta-analysis of randomized controlled trials. Arch Phys Med Rehabil. 2016;97(8):1366-1380.

14. Fernandes MR, Barbosa MA, Sousa AL, Ramos GC. Suprascapular nerve block: important procedure in clinical practice. Rev Bras Anestesiol. 2012;62(1):96-104.

15. Fernandes MR, Barbosa MA, Sousa AL, Ramos GC. Suprascapular nerve block: important procedure in clinical practice. Part II. Rev Bras Reumatol. 2012;52(4):616-622.

16. Chan CW, Peng PW. Suprascapular nerve block: a narrative review. Reg Anesth Pain Med. 2011;36(4):358-373.

17. Vanneste T, Van Lantschoot A, Van Boxem K, Van Zundert J. Pulsed radiofrequency in chronic pain. Curr Opin Anaesthesiol. 2017;30(5): $577-582$.

18. Liu A, Zhang W, Sun M, Ma C, Yan S. Evidence-based status of pulsed radiofrequency treatment for patients with shoulder pain: a systematic review of randomized controlled trials. Pain Pract. 2016;16(4):518-525.

19. Adey-Wakeling Z, Crotty M, Shanahan EM. Suprascapular nerve block for shoulder pain in the first year after stroke: a randomized controlled trial. Stroke. 2013;44(11):3136-3141.

20. Folstein MF, Folstein SE, McHugh PR. "Mini-mental state". A practical method for grading the cognitive state of patients for the clinician. $J$ Psychiatr Res. 1975;12(3):189-198.

21. Price CI, Curless RH, Rodgers H. Can stroke patients use visual analogue scales? Stroke. 1990;30(7):1357-1361.

22. Ökmen BM, Ökmen K. Comparison of photobiomodulation therapy and suprascapular nerve-pulsed radiofrequency in chronic shoulder pain: a randomized controlled, single-blind, clinical trial. Lasers Med Sci. 2017;32(8):1719-1726.

23. Wu YT, Ho CW, Chen YL, Li TY, Lee KC, Chen LC. Ultrasound-guided pulsed radiofrequency stimulation of the suprascapular nerve for adhesive capsulitis: a prospective, randomized, controlled trial. Anesth Analg. 2014;119(3):686-692.

24. Bohannon RW, Smith MB. Interrater reliability of a modified Ashworth scale of muscle spasticity. Phys Ther. 1987;67:206-207.

25. Picelli A, Dambruoso F, Bronzato M, Barausse M, Gandolfi M, Smania N. Efficacy of therapeutic ultrasound and transcutaneous electrical nerve stimulation compared with botulinum toxin type A in the treatment of spastic equinus in adults with chronic stroke: a pilot randomized controlled trial. Top Stroke Rehabil. 2014;21(Suppl 1):S8-S16.

26. Picelli A, Bonazza S, Lobba D, et al. Suprascapular nerve block for the treatment of hemiplegic shoulder pain in patients with long-term chronic stroke: a pilot study. Neurol Sci. 2017;38(9):1697-1701. 
27. Brashear A, Zafonte R, Corcoran M, et al. Inter- and intrarater reliability of the Ashworth scale and the Disability Assessment scale in patients with upper-limb poststroke spasticity. Arch Phys Med Rehabil. 2002;83(10):1349-1354.

28. Picelli A, Vallies G, Chemello E, et al. Influence of physician empathy on the outcome of botulinum toxin treatment for upper limb spasticity in patients with chronic stroke: a cohort study. J Rehabil Med. 2017;49(5):410-415.

29. Fugl-Meyer AR, Jääskö L, Leyman I, Olsson S, Steglind S. The post-stroke hemiplegic patient. 1. a method for evaluation of physical performance. Scand J Rehabil Med. 1975;7(1):13-31.

30. Golicki D, Niewada M, Buczek J, et al. Validity of EQ-5D-5L in stroke. Qual Life Res. 2015;24(4):845-850.

31. Vorster W, Lange CP, Briët RJ, et al. The sensory branch distribution of the suprascapular nerve: an anatomic study. J Shoulder Elbow Surg. 2008;17(3):500-502.

32. Borstad J, Woeste C. The role of sensitization in musculoskeletal shoulder pain. Braz J Phys Ther. 2015;19(4):251-257.

33. Boonsong P, Jaroenarpornwatana A, Boonhong J. Preliminary study of suprascapular nerve block (SSNB) in hemiplegic shoulder pain. J Med Assoc Thai. 2009;92(12):1669-1674.

34. Allen ZA, Shanahan EM, Crotty M. Does suprascapular nerve block reduce shoulder pain following stroke: a double-blind randomised controlled trial with masked outcome assessment. BMC Neurol. 2010;10:83.

35. Yasar E, Vural D, Safaz I, et al. Which treatment approach is better for hemiplegic shoulder pain in stroke patients: intra-articular steroid or suprascapular nerve block? A randomized controlled trial. Clin Rehabil. 2011;25(1):60-68.
36. Jeon WH, Park GW, Jeong HJ, Sim YJ. The comparison of effects of suprascapular nerve block, intra-articular steroid injection and a combination therapy on hemiplegic shoulder pain: pilot study. Ann Rehabil Med. 2014;38(2):167-173.

37. Lee KH, Khunadorn F. Painful shoulder in hemiplegic patients: a study of the suprascapular nerve. Arch Phys Med Rehabil. 1986;67(11):818-820.

38. Franceschini M, Iocco M, Molteni F, Santamato A, Smania N; Italian Spasticity Study Group. Management of stroke patients submitted to botulinum toxin type A therapy: a Delphi survey of an Italian expert panel of specialist injectors. Eur J Phys Rehabil Med. 2014;50(5): 525-533.

39. Smania N, Picelli A, Munari D, et al. Rehabilitation procedures in the management of spasticity. Eur J Phys Rehabil Med. 2010;46(3): 423-438.

40. Hagiwara S, Iwasaka H, Takeshima N, Noguchi T. Mechanisms of analgesic action of pulsed radiofrequency on adjuvant-induced pain in the rat: roles of descending adrenergic and serotonergic systems. Eur J Pain. 2009;13(3):249-252.

41. Van Zundert J, de Louw AJ, Joosten EA, et al. Pulsed and continuous radiofrequency current adjacent to the cervical dorsal root ganglion of the rat induces late cellular activity in the dorsal horn. Anesthesiology. 2005;102(1):125-131.

42. Tashjian RZ, Deloach J, Porucznik CA, Powell AP. Minimal clinically important differences (MCID) and patient acceptable symptomatic state (PASS) for visual analog scales (VAS) measuring pain in patients treated for rotator cuff disease. J Shoulder Elbow Surg. 2009;18(6): 927-932.
Journal of Pain Research

\section{Publish your work in this journal}

The Journal of Pain Research is an international, peer reviewed, open access, online journal that welcomes laboratory and clinical findings in the fields of pain research and the prevention and management of pain. Original research, reviews, symposium reports, hypothesis formation and commentaries are all considered for publication.

\section{Dovepress}

The manuscript management system is completely online and includes a very quick and fair peer-review system, which is all easy to use. Visit http://www.dovepress.com/testimonials.php to read real quotes from published authors. 